\title{
Ivermectin to reduce malaria transmission: a research agenda for a promising new tool for elimination
}

\author{
Carlos J Chaccour ${ }^{1,2^{*}}$, Kevin C Kobylinski ${ }^{3}$, Quique Bassat ${ }^{4,5}$, Teun Bousema ${ }^{6,7}$, Chris Drakeley ${ }^{6}$, Pedro Alonso ${ }^{4,5}$ \\ and Brian D Foy ${ }^{8^{*}}$
}

\begin{abstract}
Background: The heterogeneity of malaria transmission makes widespread elimination a difficult goal to achieve. Most of the current vector control measures insufficiently target outdoor transmission. Also, insecticide resistance threatens to diminish the efficacy of the most prevalent measures, indoor residual spray and insecticide treated nets. Innovative approaches are needed. The use of endectocides, such as ivermectin, could be an important new addition to the toolbox of anti-malarial measures. Ivermectin effectively targets outdoor transmission, has a novel mechanism of action that could circumvent resistance and might be distributed over the channels already in place for the control of onchocerciasis and lymphatic filariasis.

Methods: The previous works involving ivermectin and Anopheles vectors are reviewed and summarized. A review of ivermectin's safety profile is also provided. Finally three definitive clinical trials are described in detail and proposed as the evidence needed for implementation. Several smaller and specific supportive studies are also proposed.

Conclusions: The use of ivermectin solves many challenges identified for future vector control strategies. It is an effective and safe endectocide that was approved for human use more than 25 years ago. Recent studies suggest it might become an effective and complementary strategy in malaria elimination and eradication efforts; however, intensive research will be needed to make this a reality.
\end{abstract}

Keywords: Malaria elimination, Ivermectin, Endectocides, Vector control

\section{Background}

The last 15 years have seen renewed efforts towards controlling malaria-associated morbidity and mortality, eliminating malaria from endemic regions and even planning eventual eradication. For these efforts, several research agendas have been developed $[1,2]$. However, the gains in malaria control over the last decade are severely threatened by widespread insecticide resistance in vectors $[3,4]$ and emerging artemisinin-resistant Plasmodium falciparum $[5,6]$. These threats pose a major challenge to the vision of

\footnotetext{
* Correspondence: cchaccour@unav.es; Brian.Foy@ColoState.EDU 'Internal Medicine Department, Clínica Universidad de Navarra, Av. Pio XII 36, Pamplona 31008, Spain

${ }^{8}$ Arthropod-borne and Infectious Diseases Laboratory, Department of Microbiology, Immunology and Pathology, Colorado State University, 1692

Campus Delivery, Fort Collins, Colorado 80523-1692, USA

Full list of author information is available at the end of the article
}

the Roll Back Malaria Partnership whereby malaria is no longer a major cause of mortality by 2015 [7]. Global malaria eradication will require new tools and the implementation of an integrated approach targeting the vector and parasite in the ever changing human reservoir $[1,8]$.

Vector control has traditionally been the mainstay of malaria control in the past and is certain to remain so. The Malaria Eradication (malERA) Consultative Group on Vector Control has identified three main challenges to developing vector-targeted interventions that support elimination and eradication goals [9]. The first challenge is developing a broader range of insecticides with novel modes of action to counter current insecticide resistance among Anopheles species [10]. Secondly, to develop control methods that affect outdoor feeding and resting vectors; the current most effective tools, indoor residual

\section{Biomed Central}


spraying (IRS) and long-lasting insecticide-treated nets (LLINs), do little to prevent outdoor transmission from these vectors and can even drive exophagy and exophily among them [11]. Lastly, new interventions are needed to reduce the extremely high vectorial capacities of malaria vectors in sub-Saharan Africa [12].

\section{A potential new tool}

Endectocides are drugs that have activity against endoparasites (mainly parasitic nematodes) and ectoparasites, (they can kill arthropods that blood-feed on a treated subject). Ivermectin is the only known endectocide currently approved for human use. It is a semi-synthetic derivate from the fermentation products of Streptomyces avermectinius [13]. Ivermectin primarily agonizes glutamate-gated chloride channels in invertebrates, causing flaccid paralysis and death [13]. Glutamate-gated chloride channels do not exist in humans and other weakly sensitive channels are found in the human central nervous system, where the bloodbrain barrier limits drug access [14]. These characteristics explain ivermectin's excellent safety profile (see below). Ivermectin is one of the few drugs used in human mass drug administration (MDA) campaigns, and more than one billion treatments have been delivered over the last 25 years for controlling onchocerciasis and lymphatic filariasis [15].

Anopheles mosquitoes are particularly sensitive to very low concentrations of ivermectin relative to other vectors examined [16-18], thus offering promise for malaria control. The methods used to examine ivermectin's effects on Anopheles have been diverse (Table 1), including in vitro membrane feeding, direct blood feeding on treated animals or humans $[19,20]$, and wild mosquito collections after they have fed on humans receiving ivermectin MDA [21-23]. These studies clearly show that ivermectin is toxic to all Anopheles species examined, and at concentrations found in human blood after treatment.

Ivermectin addresses the three main challenges identified by the malERA vector control group [9]: (1) its mode of action is different from the four currently used insecticides for malaria vector control, thus it likely could circumvent the issue of emerging insecticide resistance; (2) as a systemic drug, it is ingested by all biting mosquitoes and so it will equally target indoor and outdoor-biting mosquitoes, as well as those with crepuscular activity; and, (3) the activity of the drug targets four out of the five variables of vectorial capacity [33,34], especially the most influential variable, the daily probability of mosquito survival. Ivermectin also fits many of the ideals identified in the malERA initiative, including integration with the current vector control tools, any behavioural adaptation away from biting treated humans would only be beneficial, and it is expected to affect vector population structure [35].

\section{Ivermectin's safety}

\section{The onchocerciasis control programme}

The French authorities approved ivermectin for human use in 1987. Soon after, Merck \& Co Inc. decided to donate ivermectin for onchocerciasis control and the Mectizan ${ }^{\circledR}$ Donation Program was created [13]. Since then, more than a 1.5 billion treatments have been distributed in Africa and Latin America for onchocerciasis control and another 665 million for treatment of lymphatic filariasis [15]. In this context, adverse events (AE) to ivermectin have been usually mild, transient, associated with intensity of microfilarial infection and primarily characterized as mild Mazzoti-type reactions to dying microfilaria [36]. No significant association has been found between ivermectin plasma levels and AE [37].

\section{Loa loa}

The limited number of severe neurological AE seen with ivermectin use, include encephalopathy and coma after ivermectin administration to patients who were infected with Loa loa. These reactions are closely related to the microfilarial load and are due to parasite lysis rather than drug toxicity [38]. Rapid assessment of loasis is now recommended before ivermectin MDA in Loa-endemic areas [39].

\section{Higher or multiple doses}

Several authors have evaluated the safety and tolerability of ivermectin at doses different than those indicated. Duke et al. [40] gave adult volunteers six fortnightly doses of $100 \mu \mathrm{g} / \mathrm{kg}$ without observing severe AE. Awadzi et al. [41] found no difference with controls in tolerance and early AE using doses of up to $800 \mu \mathrm{g} / \mathrm{kg}$. Guzzo et al. [42] found no significant CNS toxicity or AE in healthy volunteers taking either a single high dose of up to $2,000 \mu \mathrm{g} / \mathrm{kg}$ or repeated doses (three in a week) of up to $1,091 \mu \mathrm{g} / \mathrm{kg}$. Kamgno et al. [43] randomized Onchocercainfected volunteers to different treatment schemes and one group received $800 \mu \mathrm{g} / \mathrm{kg}$ every three months for three years (accumulated dose of $8,950 \mu \mathrm{g} / \mathrm{kg}$ ), but reported that all groups had comparable rates of AE. The high dose group reported transitory mild and subjective visual side effects more often (blurring of vision, changes in colour vision, etc.), but ophthalmological examinations revealed no structural explanation.

\section{Children, pregnancy and lactation}

Ivermectin is now licensed for the treatment of children weighing more than $15 \mathrm{~kg}$ [44].

Pacque et al. [45] carried out a prospective study in Liberia, where 14,000 people received the drug at $150 \mu \mathrm{g} / \mathrm{kg}$. Out of some 4,000 women treated, 200 were inadvertently treated during pregnancy. No significant differences in birth defect rates, development status or 
Table 1 Studies evaluating Anopheles mosquito mortality and Plasmodium transmission after imbibing blood containing ivermectin

\begin{tabular}{|c|c|}
\hline Reference & Methods \\
\hline \multirow[t]{2}{*}{$\begin{array}{l}\text { Pampiglione } 1985 \\
\text { [24] }\end{array}$} & $\begin{array}{l}\text { Feeding on impregnated cotton } \\
\text { and on treated mice. }\end{array}$ \\
\hline & $\begin{array}{l}\text { Dose: } 140-28,000 \mu \mathrm{g} / \mathrm{kg} \\
\text { (once, subcutaneous) }\end{array}$ \\
\hline \multirow{2}{*}{$\begin{array}{l}\text { lakubovich } 1989 \\
\text { [25] }\end{array}$} & Membrane and feeding on treated rabbits. \\
\hline & Dose: 340 mg/kg (once, subcutaneous) \\
\hline \multirow[t]{2}{*}{ Jones 1992 [26] } & Membrane and feeding on treated dogs \\
\hline & 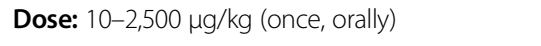 \\
\hline \multirow[t]{2}{*}{ Gardner 1993 [27] } & Feeding on treated dogs \\
\hline & Dose: 6-24 ㅆg/kg (once, orally) \\
\hline \multirow[t]{2}{*}{ Bockarie 1999 [21] } & $\begin{array}{l}\text { Field collections of engorged females } \\
\text { before and after MDA for lymphatic filariasis }\end{array}$ \\
\hline & $\begin{array}{l}\text { Dose: } 400 \mu \mathrm{g} / \mathrm{kg} \text { ivermectin }+/-6 \mathrm{mg} / \mathrm{kg} \text { DEC } \\
\text { (once, orally) }\end{array}$ \\
\hline
\end{tabular}
(once, orally)

An. stephensi

An. atroparvus

An. sacharovi

An. quadrimaculatus

An. quadrimaculatus

Significant increase in mortality. $L D_{50}=9.9 \mu \mathrm{g} / \mathrm{kg}[6.0,13.8]$ Significant decrease in oviposition and egg-hatching from survivors

An. punctulatus

Significant decrease in 9-day cumulative survival rate of Anopheles spp. collected 1-3 days post-treatment (0\%) vs those collected pre-treatment (67\%)

An. koliensis

The 48-hr survival rate of An. puctulatus collected from two houses in the a treated village the morning following MDA was $31 \%$ vs $94 \%$ from two houses of an untreated village

Pre- and post-treatment all-night landing catches showed no significant reduction in human biting rates.

Foley 2000 [20] Feeding on one treated human volunteer

An. farauti

Dose: $250 \mu \mathrm{g} / \mathrm{kg}$ (once, orally)

Fritz 2009 [28] Membrane and feeding on treated cattle Dose: $600 \mu \mathrm{g} / \mathrm{kg}$ (once, subcutaneously)

An. gambiae

An. arabiensis

12-day cumulative mortality rate of mosquitoes was $100 \%$, 95\%, 93\%, and $40 \%$ for those fed 0, 7, 10 and 14 days post-treatment vs $10 \%$ for those fed pre-treatment

Membrane feeding: $L C_{50}$ for An. gambiae s.l. was $19.8 \pm 2.8$ $\mathrm{ppb}$; no oviposition from mosquitoes fed on $>10 \mathrm{ppb}$

Cattle feeding: Total cumulative survival of An. gambiae s.s. significantly different from controls when fed up to 20 days post-treatment; no or significantly reduced oviposition when fed up to 17 days post-treatment

Mean 12-day survival time of 2.38 days $[1.52,3.24]$ for mosquitoes fed on treated subjects at 1 day post-treatment vs 5.52 days $[4.65,6.4]$ for mosquitoes fed on untreated control subjects

An. gambiae $\quad$ No effect on mosquitoes fed on treated subjects at 14 days post-treatment

An. gambiae

Kobylinski 2010 membrane feedings

[16]

Dose: NA

Sylla 2010 [23]

Field collections of engorged females before and after MDA for onchocerciasis

Dose: $150 \mu \mathrm{g} / \mathrm{kg}$ (once, orally)

An. gambiae

An. arabiensis

$L_{50}=22.4 \mathrm{ng} / \mathrm{ml}[18.0,26.9]$. At sub-lethal concentrations, significantly reduced mosquito re-blood feeding rates and a second ivermectin blood meal, even at a decreased concentration, further increased mortality

5-day cumulative survival of An. gambiae s.s. was significantly reduced from 3 treated villages vs pair-matched control villages

An. gambiae s.s. captured in treated villages 1-6 days posttreatment had significantly reduced survival $v$ those caught pre-MDA and those caught $>7$ days post-treatment

An. gambiae

Kobylinski 2011

Field collections of engorged females before and after MDA for onchocerciasis

Dose: $150 \mu \mathrm{g} / \mathrm{kg}$ (once, orally)

Butters 2012 [29] Membrane feeding

Dose: NA

An. gambiae

Sub-lethal concentrations $\left(\mathrm{LC}_{25} \& \mathrm{LC} \mathrm{C}_{5}\right.$ ) caused significant

Fritz 2012 [30] Membrane feeding Dose: NA knockdown and reduced recovery rates

For 12 days after the MDA, mean $P$, falciparum sporozoite rate was significantly reduced by $79 \%$ in 3 replicate treated villages while it increased by $246 \%$ in pair-matched control villages

An. arabiensis
$\mathrm{LC}_{50}=7.9 \mathrm{ppb}[6.2,9.9]$; oviposition among survivors was significantly reduced at $\geq 7 \mathrm{ppb}$ 


\section{Table 1 Studies evaluating Anopheles mosquito mortality and Plasmodium transmission after imbibing blood containing ivermectin (Continued)}

\begin{tabular}{|c|c|c|c|}
\hline \multirow[t]{2}{*}{$\begin{array}{l}\text { Bastiaens } 2012 \\
\text { [31] }\end{array}$} & $\begin{array}{l}\text { Feeding on treated Swiss mice, Wistar } \\
\text { rats and Cynomolgus monkeys }\end{array}$ & An. stephensi & \multirow{2}{*}{$\begin{array}{l}\text { 3-day cumulative mortality of mosquitoes fed on treated } \\
\text { mice, rats and monkeys significantly differed from controls } \\
\text { when fed up to 2, } 4 \text { and } 3 \text { days post-treatment, respectively }\end{array}$} \\
\hline & $\begin{array}{l}\text { Dose: } 200-400 \mu \mathrm{g} / \mathrm{kg} \\
\text { (different intervals, orally) }\end{array}$ & & \\
\hline \multirow{2}{*}{$\begin{array}{l}\text { Kobylinski } 2012 \\
\text { [32] }\end{array}$} & Membrane feeding & An. gambiae & \multirow{2}{*}{$\begin{array}{l}\text { Sub-lethal concentrations significantly inhibited } P \text {. falciparum } \\
\text { sporogony when fed prior to, concurrent with, and } 6 \text { and } \\
9 \text { days after infection with gametocytes }\end{array}$} \\
\hline & Dose: NA & & \\
\hline
\end{tabular}

disease patterns could be found when comparing with untreated mothers in the same population. These findings have been confirmed in hundreds of women in North Cameroon [46], Mali [47], Ghana [48] and Uganda [49]. Thus, pregnant women in onchocerciasis-endemic areas at high risk of loss of sight are no longer excluded from ivermectin treatment [50].

Ivermectin levels in human breast milk are low. After a single oral dose of $150 \mu \mathrm{g} / \mathrm{kg}$ in healthy women, Ogbuokiri et al. [51] found peak levels of $14.13+/-0.43$ $\mathrm{ng} / \mathrm{ml}$ after 6.5 hours. Therefore, a breast-fed new born would get a dose of only $2.75 \mu \mathrm{g} / \mathrm{kg}$. It is no longer recommended to exclude nursing women during MDA of Mectizan in onchocerciasis-endemic areas [50].

\section{Applying ivermectin for malaria control}

As suggested in the publications in Table 1, and by previous modelling exercises [20,23,35] there are several theoretical ways that ivermectin might be applied to help control malaria:

1) In ongoing onchocerciasis and lymphatic filariasis control campaigns, a single dose of ivermectin is administered to entire villages on a single day during MDA, with coverage rates generally between $60-80 \%$. This has positive collateral effects against soiltransmitted helminthes, [52] and ectoparasites. After MDA, most villagers' blood is toxic to biting Anopheles and this effect may last for approximately six days [23]. These toxic blood meals can kill most of the infectious adult mosquitoes, and while the numbers of adult Anopheles feeding on people can rebound quickly depending on the larval reservoir, the new population is young and most have not lived long enough to bite a gametocytaemic person and become infectious (the minimum time required for $P$. falciparum to develop in the vector is nine days). Thus, sporozoite transmission can be suppressed for weeks after MDA [22]. In this way, ivermectin MDA might be ideal to stem malaria epidemics, to interrupt brief transmission seasons or offer sustained transmission reduction if given repeatedly over longer transmission periods.
2) Recent publications have highlighted the likely benefit of combining ivermectin with drugs such as artemisinin combination therapy (ACT). ACT is highly effective in most malaria-endemic settings but does not prevent malaria-transmission in the first weeks after treatment $[53,54]$. ACT in combination with ivermectin may be an effective option for antimalarial MDA where residual transmission potential is a major concern $[55,56]$ and where mass screening and treatment (MSAT) or drug combinations fulfilling the single encounter radical cure and prophylaxis (SERCaP) profile [57] are alternative possibilities. Ivermectin would be an additive, blocking onward transmission of parasites from treated individuals by killing most Anopheles biting the person and inhibiting Plasmodium development in any surviving vectors. This would be especially important to stem the spread of resistant P. falciparum and a safe alternative for or in addition to gametocytocidal drugs [58].

3) Treatment of peridomestic animals in areas where Anopheles mosquitoes exhibit both zoophagic and anthropophagic behaviour [30], not only with ivermectin but with other classes of systemic endectocides approved for veterinary use, is expected to control the vector population size by increasing mortality, reducing fertility and flying capacity and may have further effects on transmission by inhibiting sporogony in the surviving vectors.

\section{Definitive studies}

Before ivermectin can be recommended for malaria control, large-scale community trials must be conducted to provide definitive evidence of its role in malaria control. Below are what is envisioned as the three primary trials required:

1) Single or repeated human ivermectin MDA for malaria control

Design: placebo-controlled, cluster-randomized, doubleblind trial. 
Methods: single $v s$ repeated ivermectin administration to clusters (villages) over a non-continuous malaria transmission season (e g, the rainy season) at the doses and frequency determined by previous studies.

Entomological measures:

- Mosquito survival

- Mosquito population structure

- Mosquito immigration into clusters

- Entomological inoculation rate

- Vectorial capacity

Parasite measures:

- Sporozoite rates (mosquitoes)

- Plasmodium prevalence through periodic crosssectionals

- Molecular force of infection

- NTD and ectoparasite prevalence and intensity

Clinical measures:

- Malaria clinical disease incidence as detected by passive case detection

- Serological markers of mosquito bite exposure $[59,60]$

- Anaemia prevalence

- Adverse events incidence

2) Comparison treatment of ivermectin $v s$ ivermectin + ACT

Design: individual-randomized, double-blind trial.

Methods: confirmed cases or asymptomatically infected individuals are enrolled in ACT and ivermectin + ACT arms. Doses and frequency determined by previous studies

Entomological measures:

- Colony mosquito survival and recovery after feeding directly or indirectly on blood of treated subjects

Parasite measures:

- Sporogony assessment in fed mosquitoes

- Plasmodium clearance and rate

- Gametocyte carriage and infectiousness

Clinical measures:

- Safety and toxicology (blood chemistry, haemoglobin, AEs)
- Malaria recovery rate and time to genetically determined new infections after treatments

- PK/PD parameters of ivermectin and ACT

3) Livestock ivermectin/endectocide MDA for malaria control in human population

Design: placebo-controlled, cluster-randomized, doubleblind trial.

Methods: repeated ivermectin/endectocide administration to the whole peridomestic livestock population living around clusters. Doses and frequency determined by previous studies

Entomological measures:

- Mosquito survival

- Mosquito population structure/size reduction

- Mosquito immigration into clusters

- Entomological inoculation rate

- Vectorial capacity

Parasite measures:

- Sporozoite rates (mosquitoes)

- Plasmodium prevalence/counts

- Molecular force of infection

- NTD and ectoparasite prevalence/intensity in both animals and humans

Clinical measures:

- Malaria clinical disease incidence as detected by passive case detection

- Anaemia prevalence

\section{Supportive studies}

Numerous studies are needed to fill knowledge gaps about ivermectin's effects on Anopheles, Plasmodium and transmission. Some of these studies may be necessary to complete before embarking in more specific clinical trials, such as those proposed above.

\section{Human plasma levels and mosquito mortality}

Current estimates of $\mathrm{LC}_{50}$ of ivermectin for mosquitoes are based on membrane feeding essays [16,28,32]. Simultaneous mosquito feeding and measurement of ivermectin concentration in plasma (capillary and venous blood from both men and women) can provide data for a correlation and calculation of in vivo $\mathrm{LC}_{50}$ and time post-treatment that the anti-mosquito/anti-sporogonic effect lasts. This crucial information, combined with current knowledge of 
ivermectin's pharmacokinetics, could be extrapolated into an ideal dosage and spacing of the drug for malaria control. Implied is the standardization of current assays to quantify ivermectin in blood from humans and animals and also the development of sensitive assays to detect and measure the drug in the midgut of fed mosquitoes.

\section{Confirmation of lethal effects across a range of vector bionomics}

The lethal effects of ivermectin on all Anopheles species tested so far is expected to extrapolate to exophagic and exophilic vectors, such as Anopheles minimus and Anopheles dirus in South-East Asia, Anopheles darlingi in South America, and newly identified vectors [61]. However, this must be confirmed by well-controlled studies, particularly those assessing effects on wild populations.

\section{The effects of current ivermectin MDA programmes on malaria transmission}

Only a few field trials examining the effects of ivermectin on wild mosquito populations have occurred. They have taken advantage of ongoing once-per-year anti-helminth MDA programmes to assess collateral activity against mosquito survival or changes in the sporozoite rates [22]. Reductions in mosquito survival $[21,23]$ and parasite transmission from single MDA are expected to be temporary, and the degree and duration of these reductions must be thoroughly defined to eventually move to repeat MDA trials (Definitive studies). Furthermore, effects must be compared in diverse habitats containing different vectors and malaria ecologies. In addition to direct anti-mosquito effects, measures need to be made on expected changes in Anopheles population structures (as determined by agegrading), and third-order effects on entomological inoculation rate (EIR), vectorial capacity, the molecular force of infection, and the malaria reproductive rate $\left(R_{0}\right)$.

\section{Modelling}

Very few transmission models have included ivermectin $[20,23,35]$. Current data suggests that the effect of a single ivermectin dose administered to some $80 \%$ of a village's population could have a profound effect on the age structure of the local Anopheles population, reducing transmission for up to three weeks afterwards. Further models fitted from empirical data will be essential to help predict ideal ivermectin MDA dosing and frequency, and the effects MDA might have on local mosquito population dynamics, Plasmodium transmission, and human prevalence. Models will be important to predict changes of the above outcomes based on variables such as weather, mosquito immigration, MDA compliance and other concurrent vector control measures.

\section{Anti-sporogony effects}

A recent study [32] has demonstrated that sublethal ivermectin concentrations affect $P$. falciparum transmission by inhibiting sporogony. These data suggest that ivermectin MDA may reduce transmission for a longer period than predicted based on anti-mosquito effects alone, and also enhance ivermectin's attractiveness to be used in combination with anti-malarials to prevent residual transmission and inhibit the spread of antimalarial resistance. This study needs confirmation using wild parasite isolates and with other Anopheles and Plasmodium species.

\section{Safety and formulation assessments}

A single ivermectin MDA with coverage around 80\% disrupts malaria transmission in a community by changing the structure of the local mosquito population $[22,23]$. The effect is longer than expected given the current drug formulation's short half-life. Modelling $[23,35]$ suggests that intermittent repeated administration would sustain control while minimizing mosquito and helminth resistance development. However, an alternative, single-encounter, long-lasting formulation could be less costly and more logistically feasible in MDA or MSAT approaches, and likely superior in individualized treatments meant to contain the spread of artemisininresistant Plasmodium. While the current ivermectin formulation should be tested over the short term, longer-term research should focus on finding a formulation capable of safely maintaining zero-order release for a period long enough to have a lasting impact on the malaria reproductive number $\left(\mathrm{R}_{0}\right)$. Concurrent toxicity studies must be done and possible interactions with anti-malarials and other commonly used drugs assessed.

\section{Emerging resistance}

Ivermectin is of capital importance for the control of onchocerciasis, lymphatic filariasis and for the treatment of some soil-transmitted helminths. Increasing the exposure of parasites to the drug is likely to lead to resistance in other parasites and jeopardize the success of control programmes. Indeed, ivermectin resistance has been documented in Sarcoptes scabiei in Australia and possibly in Onchocerca volvulus in Ghana [62]. Ongoing surveillance must be established in communities where ivermectin is introduced as a malaria control measure and plausible methods to delay or reverse resistance explored. Combination therapy with a second anthelmintic, such as a benzmidazole, might be effective. Likewise, proper dosing and MDA spacing might delay ivermectin resistance development in soil-transmitted helminths.

Ivermectin has a mechanism of action unrelated to that of commonly used insecticides in malaria-endemic regions. However, there must be early research on the 
possibility of resistance mechanisms in Anopheles, a better understanding of the molecular targets of ivermectin in the mosquito and possible metabolic detoxification mechanisms that could foster cross-resistance.

\section{Final comments}

Available vector control tools are not effective enough to achieve widespread malaria elimination or eradication, and innovative approaches are needed. The use of ivermectin solves many challenges identified for future vector control strategies. It is an effective and safe endectocide that was approved for human use more than 30 years ago. Recent studies suggest it might become an effective and complementary strategy in malaria elimination and eradication efforts; however, intensive research will be needed to make this a reality.

\section{Competing interests}

The authors declare that they have no competing interests.

\section{Authors' contributions}

$\mathrm{CJC}$ and BDF wrote the first draft. All authors contributed and approved the manuscript.

\section{Acknowledgements}

BDF was supported by grant 1R01Al094349-01A1 from the US National Institutes of Health-National Institute of Allergy and Infectious Diseases. The opinions or assertions contained herein are the private views of the authors, and are not to be construed as official, or as reflecting true views of the US Department of the Army or the Department of Defense.

We thank Juliane Chaccour for proofreading the manuscript.

\section{Author details}

${ }^{1}$ Internal Medicine Department, Clínica Universidad de Navarra, Av. Pio XII 36, Pamplona 31008, Spain. ' Instituto de Salud Tropical, Universidad de Navarra, Pamplona, Spain. ${ }^{3}$ Entomology Branch, Walter Reed Army Institute of Research, Silver Spring, Maryland, USA. ${ }^{4}$ Barcelona Centre for International Health Research (CRESIB, Hospital Clínic-Universitat de Barcelona), Barcelona, Spain. ${ }^{5}$ Centro de Investigação em Saúde de Manhiça (CISM), Maputo, Mozambique. ${ }^{6}$ Department of Immunology and Infection, Faculty of Infectious and Tropical Diseases, London School of Hygiene \& Tropical. Medicine, London, UK. 'Department of Medical Microbiology, Radboud University, Nijmegen Medical Centre, Nijmegen, The Netherlands. ${ }^{8}$ Arthropod-borne and Infectious Diseases Laboratory, Department of Microbiology, Immunology and Pathology, Colorado State University, 1692 Campus Delivery, Fort Collins, Colorado 80523-1692, USA.

Received: 1 March 2013 Accepted: 1 May 2013

Published: 7 May 2013

\section{References}

1. Alonso PL, Brown G, Arevalo-Herrera M, Binka F, Chitnis C, Collins F, Doumbo OK, Greenwood B, Hall BF, Levine MM, Mendis K, Newman RD, Plowe CV, Rodriguez MH, Sinden R, Slutsker L, Tanner M: A research agenda to underpin malaria eradication. PLoS Med 2011, 8:e1000406

2. Greenwood BM, Fidock DA, Kyle DE, Kappe SH, Alonso PL, Collins FH, Duffy PE: Malaria: progress, perils, and prospects for eradication. J Clin Invest 2008, 118:1266-1276.

3. Djogbenou L, Labbe P, Chandre F, Pasteur N, Weill M: Ace-1 duplication in Anopheles gambiae: a challenge for malaria control. Malar J 2009, 8:70.

4. Ranson H, N'Guessan R, Lines J, Moiroux N, Nkuni Z, Corbel V: Pyrethroid resistance in African anopheline mosquitoes: what are the implications for malaria control? Trends Parasitol 2011, 27:91-98.

5. Dondorp AM, Nosten F, Yi P, Das D, Phyo AP, Tarning J, Lwin KM, Ariey F, Hanpithakpong W, Lee SJ, Ringwald P, Silamut K, Imwong M, Chotivanich K, Lim P, Herdman T, An SS, Yeung S, Singhasivanon P, Day NP, Lindegardh N,
Socheat $D$, White $\mathrm{NJ}$ : Artemisinin resistance in Plasmodium falciparum malaria. N Engl J Med 2009, 361:455-467.

6. Dondorp AM, Yeung S, White L, Nguon C, Day NP, Socheat D, von Seidlein $\mathrm{L}$ : Artemisinin resistance: current status and scenarios for containment. Nat Rev Microbiol 2010, 8:272-280.

7. Roll Back Malaria Partnership: The Global Malaria Action Plan. Geneva; 2008. http://www.rbm.who.int/gmap/gmap.pdf (accessed 28/04/2013).

8. Cotter C, Sturrock HJ, Hsiang MS, Liu J, Phillips AA, Hwang J, Gueye CS, Fullman N, Gosling RD, Feachem RG: The changing epidemiology of malaria elimination: new strategies for new challenges. Lancet 2013. in press.

9. The malERA Consultative Group on Vector Control: A research agenda for malaria eradication: vector control. PLOS Med 2011, 8:e1000401.

10. Edi CV, Koudou BG, Jones CM, Weetman D, Ranson H: Multiple-insecticide resistance in Anopheles gambiae mosquitoes, Southern Cote d'Ivoire. Emerg Infect Dis 2012, 18:1508-1511.

11. Govella NJ, Ferguson $\mathrm{H}$ : Why use of interventions targeting outdoor biting mosquitoes will be necessary to achieve malaria elimination. Front Physiol 2012, 3:199.

12. Kelly-Hope LA, McKenzie FE: The multiplicity of malaria transmission: a review of entomological inoculation rate measurements and methods across sub-Saharan Africa. Malar J 2009, 8:19.

13. Omura S: Ivermectin: 25 years and still going strong. Int J Antimicrob Agents 2008, 31:91-98.

14. Fox LM: Ivermectin: uses and impact 20 years on. Curr Opin Infect Dis 2006, 19:588-593

15. Mectizan Donation Program: Annual Highlights; 2011. http://www.mectizan org/sites/www.mectizan.org/files/attachments/resources/Annual\% 20Highlights\%202011\%20English.pdf (accessed 28/04/2013).

16. Kobylinski KC, Deus KM, Butters MP, Hongyu T, Gray M, da Silva IM, Sylla M, Foy $\mathrm{BD}$ : The effect of oral anthelmintics on the survivorship and re-feeding frequency of anthropophilic mosquito disease vectors. Acta Trop 2010, 116:119-126.

17. Tesh RB, Guzman H: Mortality and infertility in adult mosquitoes after the ingestion of blood containing ivermectin. AmJTrop Med Hyg 1990, 43:229-233.

18. Wilson ML: Avermectins in arthropod vector management - prospects and pitfalls. Parasitol Today 1993, 9:83-87.

19. Chaccour C, Lines J, Whitty CJ: Effect of ivermectin on Anopheles gambiae mosquitoes fed on humans: the potential of oral insecticides in malaria control. J Infect Dis 2010, 202:113-116.

20. Foley DH, Bryan JH, Lawrence GW: The potential of ivermectin to control the malaria vector Anopheles farauti. Trans R Soc Trop Med Hyg 2000, 94:625-628.

21. Bockarie MJ, Hii JL, Alexander ND, Bockarie F, Dagoro H, Kazura JW, Alpers MP: Mass treatment with ivermectin for filariasis control in Papua New Guinea: impact on mosquito survival. Med Vet Entomol 1999, 13:120-123.

22. Kobylinski KC, Sylla M, Chapman PL, Sarr MD, Foy BD: Ivermectin mass drug administration to humans disrupts malaria parasite transmission in Senegalese villages. AmJTrop Med Hyg 2011, 85:3-5.

23. Sylla M, Kobylinski KC, Gray M, Chapman PL, Sarr MD, Rasgon JL, Foy BD: Mass drug administration of ivermectin in south-eastern Senegal reduces the survivorship of wild-caught, blood fed malaria vectors. Malar J 2010, 9:365.

24. Pampiglione S, Majori G, Petrangeli G, Romi R: Avermectins, MK-933 and MK-936, for mosquito control. Trans R Soc Trop Med Hyg 1985, 79:797-799.

25. lakubovich V, Zakharova NF, Alekseev AN, Alekseev EA: Evaluation of the action of ivermectin on blood-sucking mosquitoes. Med Parazitol (Mosk) 1989, 3:60-64

26. Jones JW, Meisch MV, Meek CL, Bivin WS: Lethal effects of ivermectin on Anopheles quadrimaculatus. J Am Mosq Control Assoc 1992, 8:278-280

27. Gardner K, Meisch MV, Meek CL, Biven WS: Effects of ivermectin in canine blood on Anopheles quadrimaculatus, Aedes albopictus and Culex salinarius. J Am Mosa Control Assoc 1993, 9:400-402.

28. Fritz ML, Siegert PY, Walker ED, Bayoh MN, Vulule JR, Miller JR: Toxicity of bloodmeals from ivermectin-treated cattle to Anopheles gambiae s.l. Ann Trop Med Parasitol 2009, 103:539-547.

29. Butters MP, Kobylinski KC, Deus KM, da Silva IM, Gray M, Sylla M, Foy BD: Comparative evaluation of systemic drugs for their effects against Anopheles gambiae. Acta Trop 2012, 121:34-43.

30. Fritz ML, Walker ED, Miller JR: Lethal and sublethal effects of avermectin/ milbemycin parasiticides on the African malaria vector, Anopheles arabiensis. J Med Entomol 2012, 49:326-331. 
31. Bastiaens G vGG, Hooghof J, Lindsay SW, Drakeley C, Churcher T, Verhave JP, Kocken C, Sauerwein RW, Bousema T: Duration of the mosquitocidal effect of ivermectin. MW Journal 2012, 3:1-5.

32. Kobylinski KC, Foy BD, Richardson JH: Ivermectin inhibits the sporogony of Plasmodium falciparum in Anopheles gambiae. Malar J 2012, 11:381.

33. Garrett-Jones C, Shidrawi GR: Malaria vectorial capacity of a population of Anopheles gambiae: an exercise in epidemiological entomology. Bull World Health Organ 1969, 40:531-545.

34. Macdonald G: The analysis of equilibrium in malaria. Trop Dis Bull 1952, 49:813-829.

35. Foy BD, Kobylinski KC, da Silva IM, Rasgon JL, Sylla M: Endectocides for malaria control. Trends Parasitol 2011, 27:423-428.

36. Mackenzie CD, Geary TG, Gerlach JA: Possible pathogenic pathways in the adverse clinical events seen following ivermectin administration to onchocerciasis patients. Filaria J 2003, 2(1):S5.

37. Njoo FL, Beek WM, Keukens HJ, van Wilgenburg H, Oosting J, Stilma JS, Kijlstra A: Ivermectin detection in serum of onchocerciasis patients: relationship to adverse reactions. AmJTrop Med Hyg 1995, 52:94-97.

38. Gardon J, Gardon-Wendel N, Demanga N, Kamgno J, Chippaux JP, Boussinesq $M$ : Serious reactions after mass treatment of onchocerciasis with ivermectin in an area endemic for Loa loa infection. Lancet 1997, 350:18-22.

39. Wanji S, Akotshi DO, Mutro MN, Tepage F, Ukety TO, Diggle PJ, Remme JH: Validation of the rapid assessment procedure for loiasis (RAPLOA) in the democratic republic of Congo. Parasit Vectors 2012, 5:25.

40. Duke BO, Pacque MC, Munoz B, Greene BM, Taylor HR: Viability of adult Onchocerca volvulus after six 2-weekly doses of ivermectin. Bull World Health Organ 1991, 69:163-168.

41. Awadzi K, Opoku NO, Addy ET, Quartey BT: The chemotherapy of onchocerciasis. XIX: The clinical and laboratory tolerance of high dose ivermectin. Trop Med Parasitol 1995, 46:131-137.

42. Guzzo CA, Furtek Cl, Porras AG, Chen C, Tipping R, Clineschmidt CM, Sciberras DG, Hsieh JY, Lasseter KC: Safety, tolerability, and pharmacokinetics of escalating high doses of ivermectin in healthy adult subjects. J Clin Pharmacol 2002, 42:1122-1133.

43. Kamgno J, Gardon J, Gardon-Wendel N, Demanga N, Duke BO, Boussinesq $\mathrm{M}$ : Adverse systemic reactions to treatment of onchocerciasis with ivermectin at normal and high doses given annually or three-monthly. Trans R Soc Trop Med Hyg 2004, 98:496-504.

44. Merck \& Co: Stromectrol. Package insert; 2009. http://www.accessdata.fda. gov/drugsatfda_docs/label/2009/050742s026lbl.pdf (Accessed 28/04/2013).

45. Pacque M, Munoz B, Poetschke G, Foose J, Greene BM, Taylor HR: Pregnancy outcome after inadvertent ivermectin treatment during community-based distribution. Lancet 1990, 336:1486-1489.

46. Chippaux JP, Gardon-Wendel N, Gardon J, Ernould JC: Absence of any adverse effect of inadvertent ivermectin treatment during pregnancy. Trans R Soc Trop Med Hyg 1993, 87:318.

47. Doumbo O, Soula G, Kodio B, Perrenoud M: Ivermectin and pregnancy in mass treatment in Mali. Bull Soc Pathol Exot 1992, 85:247-251.

48. Gyapong JO, Chinbuah MA, Gyapong M: Inadvertent exposure of pregnant women to ivermectin and albendazole during mass drug administration for lymphatic filariasis. Trop Med Int Health 2003, 8:1093-1101.

49. Ndyomugyenyi R, Kabatereine N, Olsen A, Magnussen P: Efficacy of ivermectin and albendazole alone and in combination for treatment of soil-transmitted helminths in pregnancy and adverse events: a randomized open label controlled intervention trial in Masindi district, western Uganda. AmJTrop Med Hyg 2008, 79:856-863.

50. Brown KR: Changes in the use profile of Mectizan: 1987-1997. Ann Trop Med Parasitol 1998, 92(Suppl 1):S61-64.

51. Ogbuokiri JE, Ozumba BC, Okonkwo PO: Ivermectin levels in human breastmilk. Eur J Clin Pharmacol 1993, 45:389-390.

52. Gutman J, Emukah E, Okpala N, Okoro C, Obasi A, Miri ES, Richards FO Jr: Effects of annual mass treatment with ivermectin for onchocerciasis on the prevalence of intestinal helminths. AmJTrop Med Hyg 2010, 83:534-541.

53. Bousema JT, Schneider P, Gouagna LC, Drakeley CJ, Tostmann A, Houben R, Githure II, Ord R, Sutherland CJ, Omar SA, Sauerwein RW: Moderate effect of artemisinin-based combination therapy on transmission of Plasmodium falciparum. J Infect Dis 2006, 193:1151-1159.

54. Sutherland CJ, Ord R, Dunyo S, Jawara M, Drakeley CJ, Alexander N, Coleman R, Pinder M, Walraven G, Targett GA: Reduction of malaria transmission to Anopheles mosquitoes with a six-dose regimen of co-artemether. PLoS Med 2005, 2:e92.
55. Okell LC, Griffin JT, Kleinschmidt I, Hollingsworth TD, Churcher TS, White MJ, Bousema T, Drakeley CJ, Ghani AC: The potential contribution of mass treatment to the control of Plasmodium falciparum malaria. PLoS One 2011, 6:e20179.

56. von Seidlein L, Greenwood BM: Mass administrations of antimalarial drugs. Trends Parasitol 2003, 19:452-460.

57. The malERA Consultative Group on Drugs: A research agenda for malaria eradication: drugs. PLoS Med 2011, 8:e1000402.

58. Baird JK, Surjadjaja C: Consideration of ethics in primaquine therapy against malaria transmission. Trends Parasitol 2011, 27:11-16.

59. Brosseau L, Drame PM, Besnard P, Toto JC, Foumane V, Le Mire J, Mouchet F, Remoue F, Allan R, Fortes F, Carnevale P, Manguin S: Human antibody response to Anopheles saliva for comparing the efficacy of three malaria vector control methods in Balombo. Angola. PLoS One 2012, 7:e44189.

60. Stone W, Bousema T, Jones S, Gesase S, Hashim R, Gosling R, Carneiro I, Chandramohan D, Theander T, Ronca R, Modiano D, Arca B, Drakeley C: IgG responses to Anopheles gambiae salivary antigen gSG6 detect variation in exposure to malaria vectors and disease risk. PLoS One 2012, 7:e40170.

61. Stevenson J, St Laurent B, Lobo NF, Cooke MK, Kahindi SC, Oriango RM, Harbach RE, Cox J, Drakeley C: Novel vectors of malaria parasites in the western highlands of Kenya. Emerg Infect Dis 2012, 18:1547-1549.

62. Osei-Atweneboana MY, Awadzi K, Attah SK, Boakye DA, Gyapong JO, Prichard RK: Phenotypic evidence of emerging ivermectin resistance in Onchocerca volvulus. PLoS Negl Trop Dis 2011, 5:e998.

doi:10.1186/1475-2875-12-153

Cite this article as: Chaccour et al.: Ivermectin to reduce malaria transmission: a research agenda for a promising new tool for elimination. Malaria Journal 2013 12:153.

\section{Submit your next manuscript to BioMed Central and take full advantage of:}

- Convenient online submission

- Thorough peer review

- No space constraints or color figure charges

- Immediate publication on acceptance

- Inclusion in PubMed, CAS, Scopus and Google Scholar

- Research which is freely available for redistribution

Submit your manuscript at www.biomedcentral.com/submit
C) Biomed Central 